\title{
AVALIAÇÃo DE PROGÊNIES dOS CAFÉS CATUAÍ AMARELO E CATUAÍ VERMELHO NA REGIÃo DE PINDORAMA (SP) $\left(^{1}\right)$
}

\author{
ANTONIO LUCIO MELLO MARTINS $\left({ }^{2}\right)$, PAULO AFONSO CLAUDINO PEDROSO $(3)$, \\ LUIZ CARLOS FAZUOLI ( ) WALLACE GONÇALVES ()
}

\begin{abstract}
RESUMO
Objetivou-se, com o presente estudo, avaliar o comportamento de quatro progênies do cultivar Catuaí Amarelo e três do Catuaí Vermelho de Coffea arabica em relação aos cultivares Caturra Amarelo e Mundo Novo da mesma espécie, na Estaçāo Experimental do Instituto Agronômico, em Pindorama. Analisaram-se a produção total e as produçōes acumuladas a cada dois anos e os valores de rendimento (relação café cereja/beneficiado), a peneira média, a porcentagem đe frutos desprovidos de sementes (porcentagem de chochos), o tipo das sementes e o peso de cem sementes tipo chato (grãos normais). Os resultados da produçāo total em um período de dezoito anos consecutivos indicaram que a progênie de Catuaí Amarelo CH 2077-2-5-62 se revelou a mais produtiva, superando inclusive o padrāo Mundo Novo. A linhagem de Caturra Amarelo (LC 476) apresentou as mais baixas produçōes. Analisando-se as produções acumuladas a cada dois anos e a total, verificou-se a possibilidade de uma avaliação precoce nesse material. As características de frutos e sementes analisadas forneceram valores considerados normais para um café de bom padrāo, possibilitando a recomendação do plantio dos cultivares Catuaí Amarelo e Catuaí Vermelho na regiāo nordeste do Estado de São Paulo.
\end{abstract}

Termos de indexação: café, Coffea arabica L., Catuaí Amarelo, Catuaí Vermelho, avaliação precoce do cafeeiro.

\section{ABSTRACT \\ EVALUATION OF CATUAÍ AMARELO AND CATUAÍ VERMELHO COFFEE PROGENIES AT THE REGION OF PINDORAMA, STATE OF SÃO PAULO, BRAZIL}

\begin{abstract}
Four progenies of the Catuaí Amarelo and three of the Catuai Vermelho cultivars of Coffea arabica L. were evaluated for yield, as well as fruits and seed characteristics in a trial carried out at Pindorama Experimental Station. Caturra Amarelo and Mundo Novo cultivars of the same specie were used as control. Latin square $9 \times 9$ design was used. Each plot had six double plants (two plants per hole) planted $3 \times 2 \mathrm{~m}$ in apart. Individual plant yield was recorded throughout eighteen years (1971-1988). It was analysed also the relation of ripe fruit weight to clean coffee weight; percentage of empty fruits; percentage of flat, peaberry and elephant beans; seed size and weight of 100 seeds for each individual plant. The Catuaí Amarelo progeny $\mathrm{CH}$ 2077-2-5-62 gave the highest total yield and Caturra Amarelo LC 476 the lowest one. Yield oscilation was similar for the highest yielding Catuai progenies and the Mundo Novo and Caturra Amarelo standards. The results indicated that the Catuai Amarelo and Catuaí Vermelho can be successfully grown at the Pindorama region.
\end{abstract}

Index terms: coffee, Coffea arabica L., Catuaí Amarelo, Catuaí Vermelho, precocious selection.

( ${ }^{1}$ ) Parte da Dissertação apresentada pelo primeiro autor à Faculdade de Ciências Agrárias e Veterinárias - Campus de Jaboticabal, da Universidade Estadual Paulista, em 1989. Recebido para publicação em 14 de fevereiro e aceito em 30 de março de 1992.

(2) Estação Experimental de Pindorama, Instituto Agronômico (IAC), Caixa Postal 28, 13001-970 Campinas (SP).

(3) Departamento de Fitotecnia, Faculdade de Ciências Agrárias e Veterinárias, Rodovia Carlos Tonanni, 14870 Jaboticabal (SP).

() Seçāo de Genética, IAC.

Bragantia, Campinas, 51(1):31-38, 1992 


\section{INTRODUÇÄO}

As lavouras cafeeiras no Brasil são formadas, em sua grande maioria, por cultivares de espécie Coffea arabica, responsáveis por um produto de boa qualidade e de maior aceitação no mercado consumidor.

Originalmente, os cafezais foram formados a partir de plantas derivadas do cultivar Arábica de C. arabica, o primeiro a ser introduzido no Brasil. Gradativamente, os cafezais foram-se diversificando pela introdução de novos cultivares, como Bourbon Vermelho e Sumatra, ou por material originado no Brasil, como Amarelo de Botucatu, Maragogipe, Caturra ou Bourbon Amarelo (Instituto Brasileiro do Café, 1986). Alguns desses cafés se revelaram mais adaptados e produtivos, como Bourbon Vermelho, Sumatra e Bourbon Amarelo, e foram multiplicados em maior escala nas regiões cafeeiras, enquanto outros, pouco produtivos, foram apenas conservados no Instituto Agronômico de Campinas ou em algumas propriedades. O Caturra, tanto o Amarelo como o Vermelho, apesar de produtivo e de ter a vantagem do porte pequeno, não foi cultivado por falta de adaptaçāo às nossas condiçōes.

Em 1943, o Instituto Agronômico de Campinas iniciou a seleção dentro de uma população de cafeeiros de Mundo Novo, hoje Urupês, de plantas rústicas, vigorosas, e de elevada produçāo, as quais, aparentemente, eram derivadas de hibridaçōes naturais entre os cultivares Bourbon Vermelho e Sumatra. As seleçōes aí efetuadas deram origem ao cultivar Mundo Novo, um dos mais produtivos e que rapidamente se expandiu por todas as regiōes cafeeiras do Brasil (Carvalho et al., 1952). Em 1949, iniciaram-se hibridaçōes entre plantas selecionadas de Caturra Amarelo e de Mundo Novo, a fim de associar a rusticidade e a produtividade do Mundo Novo ao porte reduzido do Caturra, característica de grande interesse econômico, por facilitar os tratos da lavoura e a colheita do produto. Dessas hibridaçōes e das seleçōes efetuadas nas geraçōes subseqüentes, resultaram os cultivares Catuaí Amarelo e Catuaí Vermelho, que, na realidade, constituem formas de Mundo Novo de porte reduzido (Carvalho \& Monaco, 1972).

A fim de testar a reaçāo de progênies de Catuaí Amarelo e Catuaí Vermelho em várias localidades cafeeiras com clima e solo distintos, realizaram-se numerosos experimentos, um deles na Estação Experimental do Instituto Agronômico, em Pindo- rama. As várias observações efetuadas sobre o desenvolvimento das plantas e sua produtividade em Pindorama sāo objeto do presente trabalho.

\section{MATERIAL E MÉTODOS}

A Estação Experimental de Pindorama localiza-se na regiāo noroeste de São Paulo, a $21^{\circ} 13$ 'de latitude sul e $48^{\circ} 56^{\prime}$ de longitude oeste, em solo podzólico vermelho-amarelo, tb, eutrófico, A moderado, textura arenosa média, abrupto, fase relevo ondulado. A temperatura média anual tem sido de $22^{\circ} \mathrm{C}$, a precipitação pluvial anual, de $1.328 \mathrm{~mm}$ e a umidade relativa do ar, de $71,0 \%$ (dados fornecidos pela Seção de Climatologia Agrícola do LAC). O balanço hídrico da Estação Experimental é apresentado na figura 1.

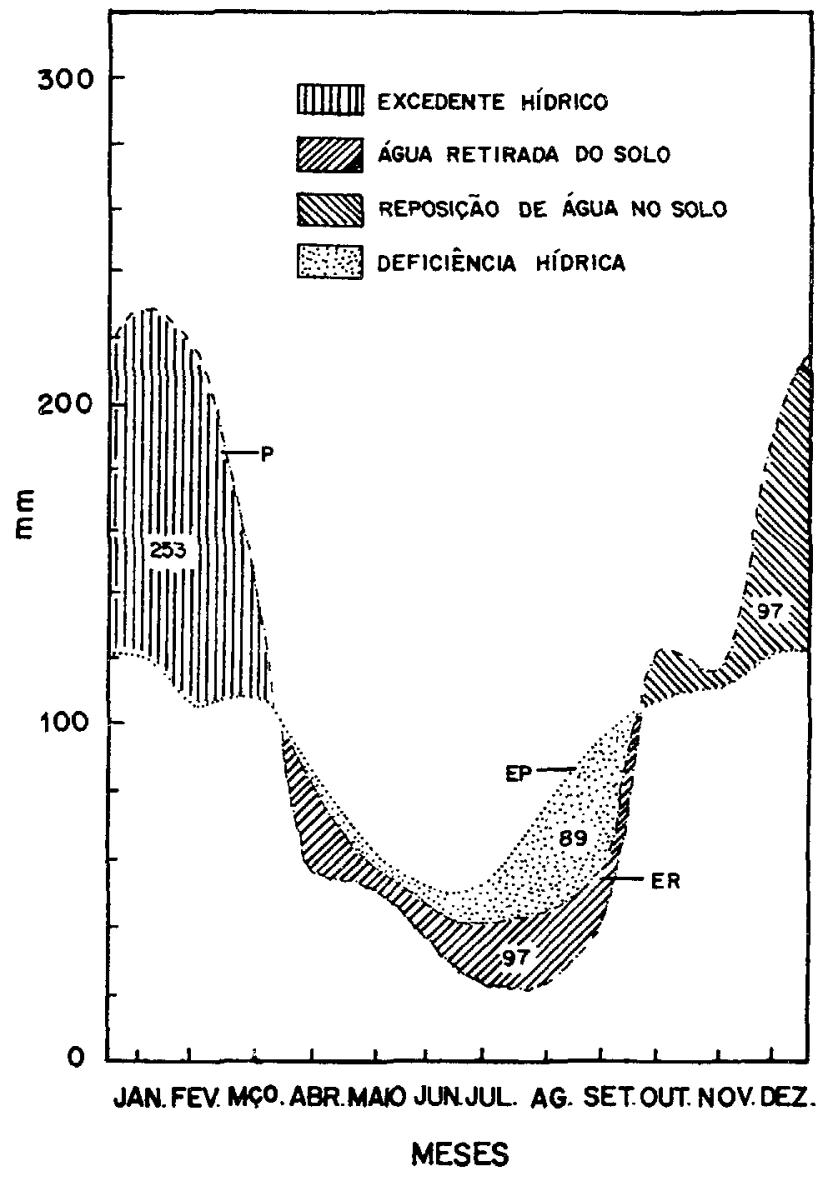

Figura 1. Balanço hídrico anual da Estação Experimental de Pindorama, segundo método de Thornthwaite \& Mather (1955): $\mathrm{P}$ (precipitação) $=1.258 \mathrm{~mm}$; EP (evapotranspiração potencial) $=1.094 \mathrm{~mm}$; ER (evapotranspiração real) deficiência hídrica $=89 \mathrm{~mm}$; excedente hídrico $=253 \mathrm{~mm}$ (Lepsch \& Valadares, 1976). 
Avaliaram-se as seguintes progênies de Catuaí Amarelo e de Catuaí Vermelho, em relação às testemunhas Caturra Amarelo e Mundo Novo:

Catuaí Amarelo - A: CH 2077-2-5-62; B: CH 2077-2-5-86; D: CH 2077-2-5-47 e I: CH 2077-2-5-43.

Catuaí Vermelho - C: CH 2077-2-5-81; E: CH 2077-2-5-24 e F: CH 2077-2-5-92.

\section{Testemunhas}

Caturra Amarelo - G: LC 476.

Mundo Novo - H: LCMP 376-4.

Adotou-se o delineamento experimental quadrado latino 9 ×9, sendo cada parcela constituída de seis covas com duas plantas por cova. Usou-se o espaçamento de $3 \mathrm{~m}$ entre as linhas e $2 \mathrm{~m}$ entre as covas, sendo a bordadura constituída por uma única linha de cafeeiros da progênie de Catuaí Vermelho CH 2077-2-5-81, em volta do experimento.

Foram avaliadas as seguintes características para estudo das progênies:

- Produção: efetuaram-se duas a três colheitas de frutos maduros de maio a julho de cada ano. A soma das três colheitas corresponde ao peso total de café maduro. No período de 1971 a 1988, todas as plantas tiveram suas produçōes anotadas individualmente.

- Rendimento: foi calculado a partir de $1 \mathrm{~kg}$ de café cereja separado da produção de cada cova em 1988. Após secagem, o café foi processado em máquina apropriada para benefício de amostras, anotando-se o peso do café obtido no processamento. A relação café cereja/beneficiado dá o valor do rendimento obtido.

- Frutos com lojas sem sementes (porcentagem de chochos): utilizou-se a técnica preconizada por Antunes Filho \& Carvalho (1957): consiste em colocar uma amostra de cem frutos de cada planta em uma vasilha com água, contando-se os que sobrenadam, pois estes apresentam uma ou mais lojas sem sementes. Esta determinação foi feita em 1973 para todas as plantas que compunham o ensaio.

- Tipos de semente: classificaram-se as sementes nos três tipos básicos: chato (grãos normais), moca e concha (grãos defeituosos), pela passagem de uma amostra de frutos secos (café em coco) em máquinas apropriadas para o beneficiamento; a seguir, as sementes obtidas foram separadas manualmente e pesadas, calculando-se as porcentagens médias de dois anos, 1972 e 1973, em relaçāo ao peso total de café beneficiado.

- Tamanho de sementes: determinou-se o tamanho das sementes do tipo chato para cada planta, utilizando-se uma série de peneiras oficiais, com orifícios que variam de $12 / 64$ a 24/64. Essa determinação foi feita em 1972 e 1973, empregando-se para análise a média obtida nos dois anos. O processo, que avalia apenas a largura da semente, pode ser utilizado em vista da correlação positiva, geralmente existente, entre o comprimento e a largura da semente (Krug, 1940).

- Peso de cem sementes: em 1988, separaram-se, nas amostras também usadas para o cálculo do rendimento, cem sementes do tipo chato, as quais foram secas até peso constante e pesadas em balança de precisão.

Análise estatística: os dados foram submetidos à análise da variância, segundo o delineamento quadrado latino $9 \times 9$. Para a significância, utilizou-se o teste "F", nos níveis de 5 e $1 \%$ de probabilidade. Nos casos de diferenças significativas, as médias foram comparadas pelo teste de Duncan, ao nível de $5 \%$.

\section{RESULTADOS E DISCUSSÃO}

Os dados de produçāo total média foram submetidos à análise da variância, que revelou diferenças significativas entre os tratamentos ao nível de $1 \%$, pelo teste F. O coeficiente de variação $(19,33 \%)$ é considerado reduzido para experimento de progênies de café. Isso se deve ao fato de as parcelas serem constituídas de seis covas e duas plantas na cova. Fazuoli (1977) chamou a atenção para a grande variabilidade observada nos experimentos de café quando as parcelas são constituídas apenas de uma cova com uma única planta, o que redunda em valores de coeficientes de variação muito elevados. No quadro 1 são indicadas as produções totais médias por progênie, a amplitude e o coeficiente de variação da produção, como também o índice relativo de produção.

A aplicação do teste de Duncan ao nível de $5 \%$ indicou que a progênie de Catuaí Amarelo CH 2077-2-5-62, a mais produtiva no período, com média acumulada de $57,09 \mathrm{~kg}$ de café maduro, difere estatisticamente das demais. As outras pro- 
gênies de Catuaí Amarelo e as de Catuaí Vermelho tiveram produçōes semelhantes, isto é, podem ser agrupadas conjuntamente com o padrão Mundo Novo, em um bloco intermediário de produtividade. A linhagem de Caturra Amarelo, usada como referência por ter sido empregada na síntese do Catuaí, apresentou a média mais baixa de produção, diferenciada estatisticamente das demais pelo mesmo teste. Resultados semelhantes foram obtidos por Carvalho et al. $(1976,1979)$, ao comparar as produções de progênies de Catuaí com as de Caturra. Atribuindo-se à linhagem Mundo Novo LCMP 376-4 um índice 100, a progênie mais produtiva $\mathrm{CH} 2077$ -2-5-62 de Catuaí Amarelo apresentou índice 67,03\% superior, e todas as demais progênies de Catuaí Amarelo ou de Catuaí Vermelho apresentaram índices superiores a 100. O comportamento da linhagem de
Mundo Novo não foi o usual, pois esse cultivar, que foi selecionado na região araraquarense, em geral tem apresentado produçóes semelhantes às do Catuaí (Carvalho et al., 1976). Tendo porte maior, a sua produçāo foi reduzida, possivelmente em decorrência do menor espaçamento utilizado no experimento.

A amplitude de variação das produçōes médias e o coeficiente de variação obtido para cada progênie não se mostram relacionados com a produção e indicam variabilidade dentro das progênies, a qual pode ser de natureza genética ou ambiental. A progênie CH 2077-2-5-62, de Catuaí Amarelo, apresentou um coeficiente de variação de produção de $20,21 \%$ e a de Mundo Novo, 22,45\%. O maior coeficiente de variação foi o da linhagem de Caturra Amarelo, 31,82\% (Quadro 1).

Quadro 1. Produção total média e amplitude de variação, em quilogramas de frutos maduros, em 1971-88, de progênies de Catuaí Amarelo e Catuaí Vermelho em comparação com os cultivares Mundo Novo e Caturra Amarelo, em experimento instalado em Pindorama (SP)

\section{Progênie( $\left.{ }^{1}\right)$}

Catuaí Amarelo

e Catuaí Vermelho

CH-2077-2-5-62 (A)

CH-2077-2-5-92 (V)

CH-2077-2-5-86 (A)

$\mathrm{CH}-2077-2-5-81$ (V)

CH-2077-2-5-47 (A)

CH-2077-2-5-24 (V)

CH-2077-2-5-43 (A)

Mundo Novo

LCMP 376-4

Caturra Amarelo

LC 476

\section{Produção}

Total média( ${ }^{2}$ ) Amplitude de variaçāo
Coeficiente Índice relativo de variação de produção $\mathrm{kg}$
$\%$

$\%$

$\begin{array}{llll}\mathrm{kg} & \mathrm{kg} & \% & \%\end{array}$


A progênie CH 2077-2-5-62, com as produçōes mais elevadas, parece ter uma ampla capacidade de adaptação, pois, em experimentos realizados em Cordeirópolis, SP (Teófilo Sobrinho et al., 1979), Ribeirão Preto, SP (Carvalho et al., 1978), Garça, SP (Costa et al., 1983), Conceição do Castelo, ES (Paulino, 1984), com climas e solos diversos, foi a que também apresentou as maiores produções.

$\mathrm{Na}$ figura 2 é indicada a variação anual de produção total da progênie $\mathrm{CH}$ 2077-2-5-62 em comparação com a de Mundo Novo e a do Caturra Amarelo: as oscilaçōes da variação anual são semelhantes, mesmo para a linhagem de menor produção do experimento, embora nos dois últimos anos, 1987 e 1988, tenha havido um acréscimo de sua produção.
Pelo quadro 2 - onde foram colocadas as produçōes totais médias, por grupos de progênies dos cultivares Catuaí Amarelo, Catuaí Vermelho, Mundo Novo e Caturra Amarelo - verifica-se que o grupo das progênies de Catuaí Amarelo (média de $45,18 \mathrm{~kg}$ ), é o mais produtivo, com um índice de 132,8 em relação ao padrão Mundo Novo, ao qual se atribuiu o índice 100 (média de $34,18 \mathrm{~kg}$ ). $O$ grupo do Catuaí Vermelho (média de 44,19 kg) apresentou um índice de 129,29, semelhante ao de Catuaí Amarelo. A amplitude de variação foi maior dentro do grupo das linhagens de Catuaí Amarelo, o que mostra uma superioridade da progênie $\mathrm{CH}$ 2077-2-5-62, mesmo entre as demais que compōem esse grupo.

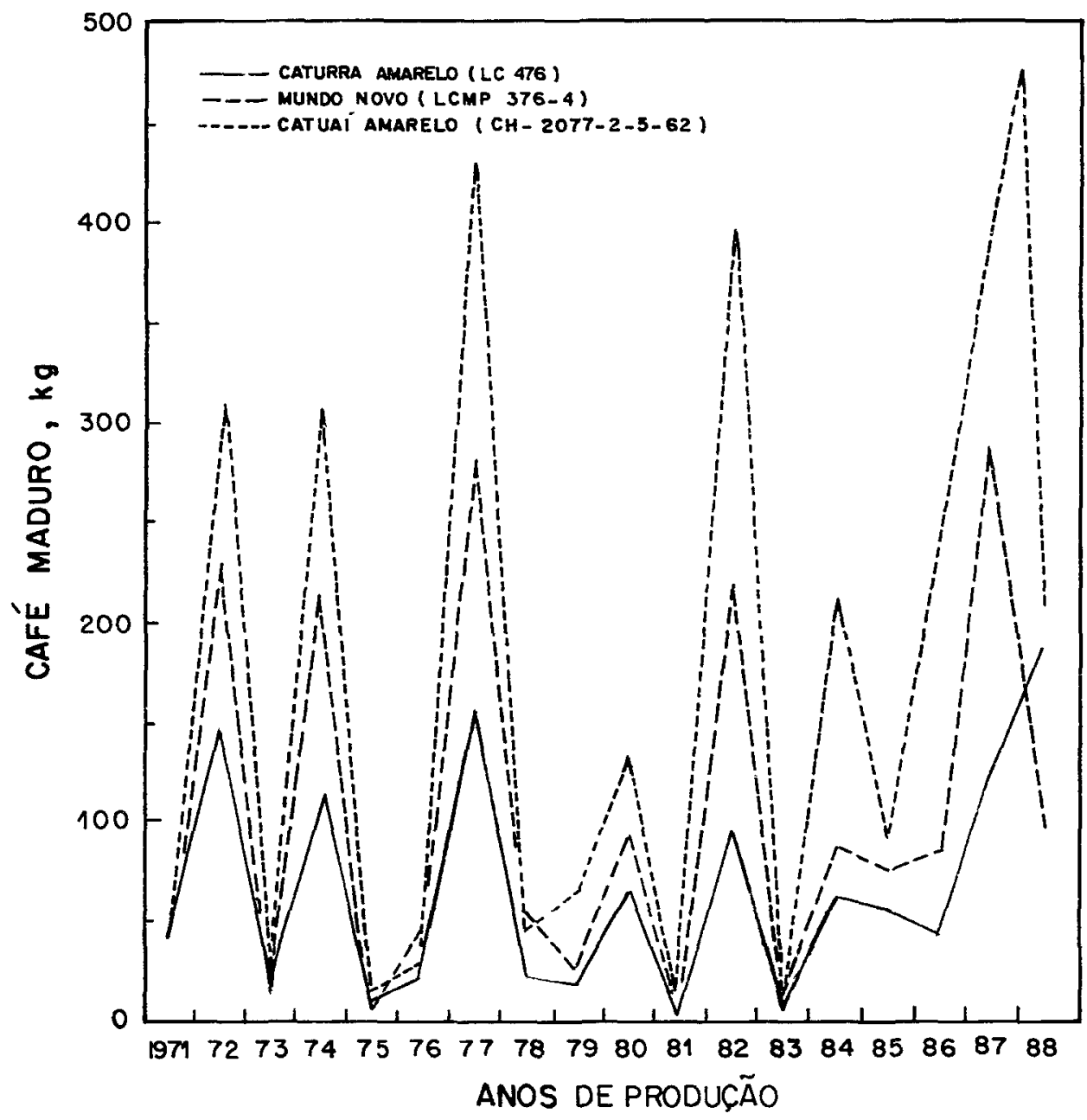

Figura 2. Produção total de 108 cafeeiros (54 covas), em quilogramas de frutos maduros, das linhagens de Caturra Amarelo e Mundo Novo e da progênie de Catuaí mais produtiva do experimento de 1981-88. 
Quadro 2. Produção total média, em quilograma de frutos maduros, em 1971-88, dos grupos de progênies de Catuaí Amarelo e Catuaí Vermelho

\begin{tabular}{lcccc}
\hline Cultivar & \multicolumn{2}{c}{ Produção total } & $\begin{array}{c}\text { Amplitude } \\
\text { de variação }\end{array}$ & $\begin{array}{c}\text { Índice relativo } \\
\text { de produção }\end{array}$ \\
\cline { 2 - 4 } & Progênie & Média & $\mathrm{kg}$ & $\mathrm{kg}$ \\
& $\mathrm{n}-$ & 45,18 & $22,18-80,42$ & 132,18 \\
Catuaí Amarelo & 4 & 44,19 & $31,71-73,14$ & 129,29 \\
Catuaí Vermelho & 3 & 34,18 & $22,70-42,19$ & 100,00 \\
Mundo Novo & 1 & 22,29 & $13,00-35,69$ & 65,21 \\
Caturra Amarelo & 1 & & & \\
\hline
\end{tabular}

Os coeficientes de correlação, calculados entre as produçōes totais médias das progênies após 2,4 , 6 e 8 anos de colheitas acumuladas, em relação às produçōes após 18 anos, encontram-se no quadro 3.

Quadro 3. Coeficientes de correlação obtidos entre as produções totais de dois anos (1971-72), quatro (1971-74), seis (1971-76) e oito (1971-78) e produção total obtida em 1971-88, para as progênies e linhagens do experimento

\begin{tabular}{cc}
$\begin{array}{c}\text { Anos iniciais } \\
\text { de produção }\end{array}$ & $\begin{array}{c}\text { Coeficiente } \\
\text { de correlação }\end{array}$ \\
\hline 2 & $0,49^{* *}$ \\
4 & $0,70^{* *}$ \\
6 & $0,72^{* *}$ \\
8 & $0,87^{* *}$ \\
\hline
\end{tabular}

** Significativo ao nível de $1 \%$.

Nota-se que as produções verificadas aos 2 anos já se acham correlacionadas com as obtidas aos 18 , mas os coeficientes vão-se tornando maiores, como era de esperar, com o acréscimo do número de colheitas. Com quatro colheitas o valor do coeficiente de correlação foi 0,70 (Quadro 3). Uma análise mais profunda sobre a possibilidade da avaliação com quatro colheitas no Catuaí foi efetuada por Martins (1989). Para progênies de Mundo Novo, Fazuoli (1977) verificou correlação significativa a partir da produção de 4 anos, em relação à de 17 anos, indicando a possibilidade de interpretação dos dados com base nas quatro primeiras produções. Uma avaliação assim precoce foi também efetuada por Carvalho (1952), Antunes Filho \& Carvalho (1957), Monaco (1960), Carvalho et al.(1973, 1975).

No quadro 4, são indicados os valores referentes às características de frutos (rendimento e porcentagem de frutos com lojas vazias) e de sementes (peneira média, tipos e peso de cem sementes).

Os valores relativos aos parâmetros rendimento, porcentagens de frutos com lojas vazias, tipos de sementes, peneira média e peso de cem sementes, nas diversas progênies avaliadas, não apresentaram os melhores índices para a progênie mais produtiva, mostrando nāo haver relaçāo direta entre estes e a produtividade e mesmo entre si, mas todos os valores sâo considerados normais para os padrōes de seleção hoje adotados. 
Quadro 4. Médias relativas a rendimento, frutos com lojas vazias, tipo de sementes, peneira média e peso de cem sementes de progênies de Catuaí Amarelo e Catuaí Vermelho em comparação com os cultivares Mundo Novo e Caturra Amarelo em experimento instalado em Pindorama (SP)

$$
\text { Progênies } \quad \text { Rendimento }\left({ }^{1}\right) \underset{\text { lojas vazias }}{\text { Frutos com }} \frac{\text { Tipo de sementes }}{\operatorname{Chato}\left({ }^{1}\right) \quad \operatorname{Moca}\left({ }^{1}\right) \quad \operatorname{Concha}\left({ }^{1}\right)}
$$

Peneira Peso de 100 média $\left({ }^{1}\right)$ sementes $\left({ }^{1}\right)$

\begin{tabular}{|c|c|c|c|c|c|c|c|}
\hline & & & $\ldots$ & & & & g \\
\hline \multicolumn{8}{|l|}{ Catuaí Amarelo } \\
\hline CH 2077-2-5-62 & $6,02 \mathrm{ab}$ & 9,91 & $82,96 a-c$ & $13,96 \mathrm{a}-\mathrm{c}$ & $3,59 \mathrm{bc}$ & $16,91 \mathrm{ab}$ & $11,27 \mathrm{ab}$ \\
\hline CH $2077-2-5-86$ & $6,01 \mathrm{ab}$ & 9,91 & $81,74 \mathrm{bc}$ & $14,40 \mathrm{bc}$ & $3,78 b c$ & $16,91 \mathrm{ab}$ & $10,99 \mathrm{~b}-\mathrm{d}$ \\
\hline CH 2077-2-5-47 & $5,66 \mathrm{a}$ & 8,44 & $83,44 a b$ & $13,18 b c$ & $3,29 \mathrm{c}$ & $16,67 \mathrm{bc}$ & $10,79 \mathrm{~cd}$ \\
\hline CH $2077-2-5-43$ & $5,69 a$ & 9,94 & $83,10 a-c$ & $12,37 \mathrm{bc}$ & $4,81 \mathrm{a}$ & $17,12 \mathrm{a}$ & $10,80 \mathrm{~cd}$ \\
\hline \multicolumn{8}{|l|}{ Catuaí Vermelho } \\
\hline СH 2077-2-5-92 & $5,67 \mathrm{a}$ & 7,44 & $84,68 \mathrm{a}$ & $11,89 \mathrm{c}$ & $3,39 \mathrm{c}$ & $16,25 \mathrm{ab}$ & $11,18 \mathrm{bc}$ \\
\hline СH $2077-2-5-81$ & $6,30 \mathrm{~b}$ & 7,56 & $83,44 a b$ & $13,46 a-c$ & $3,24 c$ & $16,81 b$ & $10,82 \mathrm{~cd}$ \\
\hline CH 2077-2-5-24 & $6,04 a b$ & 8,78 & $80,94 c$ & $15,60 \mathrm{a}$ & $3,68 \mathrm{bc}$ & $16,82 b$ & $10,74 d$ \\
\hline \multicolumn{8}{|l|}{ Mundo Novo } \\
\hline LCMP $376-4$ & $5,69 a$ & 5,66 & $84,76 a$ & $12,18 b c$ & $3,04 c$ & $17,12 \mathrm{a}$ & $11,58 \mathbf{a}$ \\
\hline \multicolumn{8}{|l|}{ Caturra Amarelo } \\
\hline LC 476 & $5,70 \mathrm{a}$ & 8,33 & $81,32 \mathrm{bc}$ & $14,39 b c$ & $4,23 \mathrm{ab}$ & $16,54 \mathrm{c}$ & $10,08 \mathrm{c}$ \\
\hline Valor de F & $3,71^{* *}$ & & $3,62^{* *}$ & $2,86^{*}$ & $4,82^{*}$ & $4,71^{* *}$ & $10,34^{* *}$ \\
\hline C.V.(\%) & 6,26 & & 2,6 & 16,04 & 20,51 & 1,57 & 3,59 \\
\hline
\end{tabular}

(1) Médias seguidas de, pelo menos, uma letra em comum, não diferem entre si pelo teste de Duncan a $5 \%$.

\section{CONCLUSÕES}

1. Todas as progênies de Catuaí Amarelo ou Catuaí Vermelho analisadas mostraram variabilidade anual de produção semelhante, da mesma forma que o padrão Mundo Novo e a linhagem de Caturra Amarelo.

2. A progênie mais produtiva do experimento foi a de prefixo CH 2077-2-5-62 de Catuaí Amarelo.

3. Apesar de se ter uma correlação positiva entre as produções das progênies dos dois primeiros anos com as acumuladas nos 18 anos, uma avaliação mais precoce do experimento poderá ser efetuada com segurança utilizando as produções dos quatro primeiros anos.

4. As características de frutos e sementes das progênies de Catuaí Amarelo e Catuaí Vermelho foram consideradas normais e de bom padrāo.

5. Os cultivares Catuaí Amarelo e Catuaí Vermelho apresentaram bom comportamento em Pindorama, em relação ao desenvolvimento e produçāo, podendo, assim, ser recomendados para plantio na região. No entanto, deve-se dar ênfase à linhagem $\mathrm{CH}$ 2077-2-5-62, de Catuaí Amarelo. 


\section{REFERENCIAS BIBLIOGRÁFICAS}

ANTUNES FILHO, H. \& CARVALHO, A. Melhoramento do cafeeiro: XI. Análise da produção de progênies e hibridos de Bourbon Vermelho. Bragantia, Campinas, 16:175-195, 1957.

CARVALHO, A. Melhoramento do cafeeiro: VI. Estudo e interpretação, para fins de seleção, de produções individuais na variedade Bourbon. Bragantia, Campinas, 12:179-200, 1952.

CARVALHO, A.; KRUG, C.A.; MENDES, J.E.T.; ANTUNES FILHO, H.; MORAIS, H. de; ALOISI SOBRINHO, J.; MORAIS, M.V. de \& ROCHA, T.R da. Melhoramento do cafeeiro: IV. Café Mundo Novo. Bragantia, Campinas, 12:97$-129,1952$.

CARVALHO, A. \& MONACO, L.C. Transferencia do fator Caturra para o cultivar Mundo Novo de Coffea arabica. Bragantia, Campinas, 31:379-399, 1972.

CARVALHO, A.; MONACO, L.C.; ALVES, S. \& FAZUOLI, L.C. Melhoramento do cafeeiro: XXXIII. Produtividade e outras características de vários cultivares em Monte Alegre do Sul. Bragantia, Campinas, 32:245-260, 1973.

CARVALHO, A.; MONACO, L.C. \& FAZUOLI, L.C. Mlehoramento do cafeeiro: XXXV. Altura e profundidade das plantas e características das sementes de progênies e hibridos de café plantados a uma e quatro plantas por cova. Bragantia, Campinas, 34:295-308, 1975.

CARVALHO, A.; MONACO, L.C. \& FAZUOLI, L.C. Melhoramento do cafeeiro: XXXVI. Produtividade do café de porte pequeno com poda dos ramos inferiores. Bragantia, Campinas, 35(2):397-404, 1976.

CARVALHO, A.; MONACO, L.C. \& FAZUOLI, L.C. Melhoramento do cafeeiro: XXXIX. Produtividade e características de progenies S2 e S3 de Mundo Novo e Bourbon Amarelo e de hibridos entre esses cultivares. Bragantia, Campinas, 37:129$-138,1978$.

CARVALHO, A.; MONACO, L.C. \& FAZUOLI, L.C. Melhoramento do cafeeiro: XL. Estudos de progênies e hỉbridos de café Catuaí. Bragantia, Campinas, 38:203-216, 1979.
COSTA, W.M. da; FAZUOLI, L.C.; CARVALHO, A.; NUNES, J.B.P. \& BARONI, R.L. Seleçōes regionais de Catuaí: comportamento de populaçōes na região da Alta Paulista. In: CONGRESSO BRASILEIRO DE PESQUISAS CAFEEIRAS, 10., Poços de Caldas, 1983. Anais. Rio de Janeiro, IBC-GERCA, 1983. p.104-105.

FAZUOLI, L.C. Avaliação de progênies de café Mundo Novo (Coffea arabica L). Piracicaba, 1977. 146p. Dissertaçāo (Mestrado em Genética e Melhoramento de Plantas) ESALQ/USP, 1977.

INSTITUTO BRASILEIRO DO CAFÉ. Grupo Executivo de Racionalização da Cafeicultura. Coltura de café no Brasil: pequeno manual de recomendações. Rio de Janeiro, 1986. 215p.

KRUG, C.A. O cálculo da "Peneira Média" na seleçāo do cafeeiro. Revista do Instituto de Café do Estado de São Paulo, São Paulo, 15(156):123-128, 1940.

LEPSCH, I.F. \& VALADARES, J.M.A.S. Levantamento pedológico detalhado da Estaçâo Experimental de Pindorama, SP. Bragantia, Campinas, 35(2):13-40, 1976.

MARTINS, A.L.M. Avaliação de progênies de Catuaí (Coffea arabica L.) na regiāo de Pindorama - SP. Jaboticabal, 1989. 67p. Dissertaçāo (Mestrado em Agronomia) -UNESP-FCAV, 1989.

MONACO, L.C. Melhoramento do cafeeiro: XVII. Seleção do café Maragogipe A.D. Bragantia, Campinas, 19(1):459-492, 1960.

PAULINO, A.J. Avaliaçáo do germoplasma de linhagens de Coffea arabica no Espírito Santo. In: CONGRESSO BRASILEIRO DE PESQUISAS CAFEEIRAS, 11., Londrina, 1984. Resumos. Rio de Janeiro, IBC-GERCA, 1984. p.89-90.

TEÓFILO SOBRINHO, J.; COSTA, W.M. da \& FAZUOLI, L.C. Produtividade do cultivar Catuaí de Coffea arabica em Cordeirópolis. In: CONGRESSO BRASILEIRO DE PESOUISAS CAFEEIRAS, 7., Araxá, 1979. Resumos. Rio de Janeiro, IBC-GERCA, 1979. p.116-117.

THORNTHWAITE, C.W. \& MATHER, J.R. The water balance. Centerton, Drexel Institute of Technology - Laboratory of Climatology, 1955. 104p. (Publications in Climatology, v.8, n.1) 